International Journal of Linguistics, Literature and Translation

ISSN: 2617-0299 (Online); ISSN: 2708-0099 (Print)

DOI: 10.32996/ijltt

Journal Homepage: www.al-kindipublisher.com/index.php/ijltt

\title{
The Feminine Cultural Politics Essentialism and Popular Imagination Liberality in Nuruddin Farah's Sardines (1982)
}

\author{
Souleymane Diallo 8 (D) \\ Postcolonial and African Studies Laboratory, Anglophone Department, Cheikh Anta Diop University, Dakar, Senegal \\ $\triangle$ Corresponding Author: Souleymane Diallo, E-mail: jahsalomon@gmail.com
}

ARTICLE INFORMATION

Received: March 14, 2021

Accepted: April 02, 2021

Volume: 4

Issue: 4

DOI: $10.32996 /$ ijllt.2021.4.4.4

\section{KEYWORDS}

Pre-political Status, Liberal Imagination, Determinism, Revisionism, Self-appropriation, Deconditioning, Metapsychological, Transmutation, Identity

\section{ABSTRACT}

Throughout the development of this fiction, Nuruddin Farah exposes the issues of the sphere of origin. In fact, the run of Sardines exhibits the question of the patriarchal reality of ideas, and then, emphasizes a feminine self-consciousness, which through its evolutionary source and perfecting method disrupts the traditional construction of narrative-based essentially on custom of symbol. Through the implemented study of a new feminine ontological aspect, the logic of Sardines remains in a realistic and structural redefinition of social epistemology. In this line, within the realm of social agency, the feminine new ontological discourse dismantles the macro-structural establishment within which identity is constructed. In this perspective, this paper aims to focus on voluntary feminine emancipation and its psychological and cognitive value. Furthermore, through the discourse of a new politics of identity, this paper seeks to unveil the manner socio-political conservatism reality annihilates the truth of the individual. Therefore, the consequence of this article is expected to underscore the feminine approach of a new historical materialism.It remains an attempt to display the implied practical mode of communication, which appears different from the apparent reality of the patriarchal mode, the manner Farah creates a discourse of reconstruction and a scientific observation of the real.

\section{Introduction}

The didactic process imbedded in the restructuration of the domain of ideas, and imagination unveils a feminine adaptive value and a psychological mechanism that infuses a well-considered desire to redefine the notion of object, imagination and perception. This ostentatious, voluntary mimetism introduces a feminine qualitative and a specific narrative identity. Therefore, the permanent character of imagination imposes itself within a realm of reality that destabilizes the conservative approach of representation. Thereby, through a creative imagination, the established feminine discursive intelligence spontaneously, emphasis on an inductive method within experience becomes the basis of practical reasoning.

In this run, the organization of the feminine subversive intellectual contents abode in deconstructing the domain of collective ontology. The quantitative reading and the qualitative inquiry of this object grants to the feminine imagination, an intimate nature to develop a gathering constituent figure as regards the creation of collective identity. The feminine intellectual liberalism becomes a body, a causative substance, contributing to the construction of a feminine active invisibility. The object of thought and the perception of intellectual act, through the feminine different ontological aspect of narrative establish intelligible relations as regards the sociological approach of collective agency. Consequently, the popular creative imagination interwoven through the ontological width of the feminine narrative becomes entangled in an empirical deconstructionism of action and passive visibility.

In this perspective, the main line of this paper puts the focus on the will and the interest of this liberal imagination and its capacities to demonstrate the incongruities that sustain the connections between socio-economic structures and political

\begin{tabular}{l|l|l}
$\mathbf{K}$ & $\mathbf{C}$ & AL-KINDI CENTER \\
$\mathbf{R}$ & $\mathbf{D}$ & FOR RESEARCH AN
\end{tabular} $\mathbf{R}$ D DEVELOPMENT Your gateway to world-class research

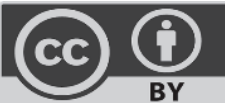

Published by Al-Kindi Center for Research and Development, London, United Kingdom. Copyright (c) the author(s). This open access article is distributed under a Creative Commons Attribution (CC-BY) 4.0 license 
organization. Through the paternalistic and public opinion run, and by focusing consideration on a feminine liberal imagination, this article seeks to underline the feminine pre-political status that observes the primitive nature, the political centralization, and the determinism principles of the institution of their Muslim civilization. In the first run, I deal with the discursive processes of the feminine popular imagination liberality; in the subsequent run, I argue in various features the psychological function of a conceptual and rational object propelling a spiritual, temporal, and relational revisionism; in the third run, I introduce the feminine descriptive language providing to the feminine liberal imagination a progressive sensible intellectualization and a wellconsidered construction of principles in the perspective to contradict the emotional systematization and rationalization of the patriarchal political constitution.

\section{The Psychological Acquisition of Literary Expression}

The material and practical political concern of Sardines revolves around the principle object of transposing the feminine primitive social order process toward a politico-economic active agency. In effect, the faculty of imagination, and the exhibition of a feminine collective memoir through the contemporary development of civilization unveil a growing predicament of sociopolitical identity. Thus, the aesthetic reality of language introduces phases of resistance to the truth of the patriarchal perception of political liberty. By this way, the feminine self-appropriation gets through the annihilation of the patriarchal-self, wherein is ingrained an utterly exhausted segment of doctrinal absolutism. Consequently, the fantastic and the real embedded through the feminine descriptive discourse appear, as an adaptive significance of a psychological mechanism, which attempts to the obliteration of the feminine passive inconspicuousness. This realm becomes more ubiquitous when the Personal Narratives Group asserts that:

This political climate effected corresponding upheaval in the academic world. If experience was open for redefinition, a crisis in representation was inevitable. As this hegemonic world view was challenged, the canons of all fields were questioned. Scholars with both the humanities and social sciences raised the question of whose lives had been made exemplary in contemporary and historical studies, and asked further what impact on our understanding of human experience the inclusion of different life experience would have (Personal Narratives Group, 1989, p.3).

The rational axis of this descriptive, detailed and animated technic interests itself in the falling off the sensitive aspects connected to phallocentric projective psychology, representative genealogy, and the domain of otherness. Therefore, the feminine moral and intellectual acquiring would-be series of transmutation, a trans-individual acknowledgment of value essentially connected to the truth of history and to a deconditioning method of religious, legal and linguistic ethnology. Certainly, the feminine social ontology reconciliation enacts an expressive silence, in the run, an open and peripatetic sensitive physiognomy yields a structured stage within is permeated an imaginary exoticism with an interactive and chronological method. Correspondingly, this realm remains one of the Muslim feminine imagination liberalities that go beyond essentialist sets, in the dynamic, to provide against disjunctive and hypothetic judgment:

Then Yeat's "Prayer to my Daughter" which Medina had translated into Somali. And in the place of her poetic-memory, she saw little girls, chattery with joy, who held the world's heart in the glowing smiles of their teeth. But when these innocuous things grew up, when the Kurdish girl, the Bengali girl, the Irish or the Somali grew into womanhood - what would be their lot? In Somalia, fifteen per cent of them wouldn't live to celebrate their first birthday. Was that the tragedy of which Nietzsche spoke? (Farah, 1982, p.118)

Thus, this characteristic of imagination becomes an object of thought encompassing an intellectual act, which inserts this feminine narrative within a meta-psychological process. This scheme alters the patriarchal ironical morality, as it concerns social structuration and the feminine apperception of essence and relation subject par rapport the transmutation of time and space. Within this respect, the collective origin of the subsequent value of substance and appearance of this feminine liberal imagination is due to the construction of a material body, within is erected an intelligible relation through a gathering series ranging from instruction, society, and organization. Therefore, the fundamental aphorism of this feminine imagination liberality in Sardines introduces a shift on the moral axiological sphere; in the sense, contemporary transfiguration installs a transubstantiation state as regards identifying procedures. Therein, we grasp the Personal Narratives Group construction while they argue that:

Personal narratives are particularly rich sources because, attentively interpreted, they illuminate both the logic of individual courses of action and the effects of system-level constraints within which those courses evolve. Moreover, each life provides evidence of historical activity- the working out within a specific life situation of deliberate courses of action that turn can undermine or perpetuate the conditions and relationships in which the life evolved (Personal Narratives Group, 1989, p.11). 
The productive dimensions of this imagination become a process of evolution through the doctrinal absolutism transformation of Muslim civilisation's socio-political institutions. Moreover, through the order of the patriarchal subjectivity the exuberance of the feminine imagination stands as a psychological reflexive method, a transitive causality, and a symmetric rapport construction between the social economic structures and the ideology and mystical nature. This sphere according to the consolidation of the complete feminine mental operations, demonstrates that the absolutism of the patriarchal political power depends on the material and representative renunciation of intellective faculties. In this respect; the feminine psychological act of intellect is due to external socio-political transformation. Then, the involved imaginative process becomes a punctual transforming power, which shows that the effects corresponding to their patriarchal cultures should not be the repository of the feminine modern identification paradigms. Through the introduction of a feminine narrative code, Nuruddin Farah underlines that the discursive intelligent of his female characters demonstrate that their Muslim surrounding's conservative cultural work does not correspond to contemporary models of socio-political expansion. In this run, Farah writes:

She casts her eyes, like a net, in the direction of her mother, hoping to catch a glimpse of that far-fetched look so that Medina would help her: how could she draw, how could she capture and present the streak of guilt in the eyes of subject which she traced with a pencil? ....whereas the line of her ideology mapped the eighty-one crossing the eighteen: O God who art in Heaven, how many are Your names? Only ninety nineAmen! ... "Dye it socialist red, with the red star of victory (and bureaucracy) prominently placed in its proper central position. And in the background trace lightly a crescent, like a half-cup. Don't forget the sword whose blunted edge is good for female infibulation" (Farah, 1982, pp. 20-21).

As a result, the feminine imaginative approach of understanding appears as a new politics of identity, within which feminine political status rehabilitation makes sense to the realm of ontological difference, and equity. This new politics of identity regards the realm of imagination as a formal reality, wherein revocatory acts are raised to deconstruct the paternalistic objective reality. In this run, this intellectual activity systematizes a self-determining sphere within the feminine new politics of identity makes objection to all form of idiosyncratic partiality and any voluntary misrepresentation of socio-economic and political reality. At this stand, it appears that the active imagination ingrained in the growth of the feminine consciousness constitutes a permanent mimetism. Moreover, its versatile organism installs in the psyche of the feminine there-being a methodic intellectual construction that allows the realization and the relational adaptation to a new order of agency and pluricultural power-oriented norm.

\section{From an Individualistic Expression to an Inner Essence Lyricism}

In the run of Sardines, the feminine imaginative backdrop constitutes a state of refusal with regard to demanding conformism and gregarious instinct. The individualistic countenance inserted in the discursive intelligence that withstands the feminine new political identity, upholds a temporal and spiritual axes of orientation. This realm is well illustrated by Michel A. Paludi when he argues that:

Gender-reform feminism emphasizes similarities between women and men rather than focusing on differences between them. Gender-resistance feminism holds that formal legal rights alone will not end gender inequality; male dominance is too ingrained into social relations. Gender-resistance feminism focuses on how men and women are different—cognitively, emotionally, and socially—and urges women to form women-centered organizations and communities. Gender-rebellion feminism looks at the interrelationships among inequalities of sex, race, ethnicity, social class, and sexual orientation (Paludi, 2010, p. XV).

The capacity of transmission of this system displays the individual aptitude and the basic socio-political predispositions looking for the maturity of the right and accountabilities of the feminine being. Pauline Johnson furthers this sight:

To a contemporary feminism concerned to establish the specificity, the legitimate difference, of the feminine, a post-modern ethos which repudiates any hierarchisation of world-views and endorses a democratic pluralism as the only defensible value appears as the more attractive option Johnson, 1990, p. 100).

Therefore, through aesthetic spiritualism and the symbolic constant individualistic manifestation, Sardines' involved feminine voice distorts the illusory and impulsive conception of collectivity. Farah strengthens this context: "The General's power and I are like two lizards engaged in a Varangian dance of death; we are two duelists dancing the tarantella in which they challenge their own destiny" (Frah, 1982). This discursive thought impels the feminine there-being to develop a desire of initiative, and individualistic consideration, in the perspective to install another type of narrative, which provides an awareness of difference on the scheme of individual and public liberties: 
... Neglecting the context from which a life is narrated invites the risk of misunderstanding and misinterpretation. Acknowledging the centrality and complexity of context reveals the range of experiences and expectations within which women live, and provides a vital perspective from which to interpret women's ways of navigating the weaves of relationships and structures which constitute their world (Personal Narratives Group, 1989, p. 19).

Correspondingly, within the direct formal power that constructs the axes of social conformism, the feminine liberal imagination puts forth systematic discordant reactions par rapport the androcentric perception of the socio-political institutions and civilization. In this manner, the feminine narrative appears as an intellective mechanism that characteristically reveals the ethical, legal and despotic domination of moral traditionalism and cultural ideologies:

The world, represented by the room's four walls, shifted, the world revolved round the sun, the sun revolved round the universe and the two together gave birth to the image of the wicked serpent biting its own tail. Should she sing... The feeling returned, the feeling which had to do with her being the one person who had survived a ruinous traumas, an arduous journey, a disastrous duel; she felt that as though she were playing with people who weren't seasoned by time, whose experiences were limited if not short-lived. She was livid with herself. Imagine being one among the few with sight in a blind country (Farah, 1982, pp. 49-50).

Thus, the new feminine discourse in Sardines grows into a counter-preponderance account. It embodies functioning foundations of understanding within the trail of reality and the objective reality demonstrates, socio-political conservatism reality denies the truth of the intrinsic causes and quality of the individual. By this way, the feminine formative philological order, and the ontological and normative moral interleaved through their intellectual construction of a new politics of identity, removes itself from the phallus epiphenomenalism perception of collectivity. Farah highlights this view: "A boy and a girl. Water and fire. Don't you see the contrast, the elements of life which complement each other? A boy conceived in the full swing of normalcy; a girl conceived in the concealed darkness of tradition[10]". This consideration develops within the new feminine narrative, an analytical relation within which the patriarchal authoritarian hermetism undergoes a structural and functional volatility. Correspondingly, the feminine progressive structural psycholinguistic in Sardines, upholds a differential psychology, and displays the causes and features to react against the masculine dominant ideology. In this dynamic, the inner essence dimension of this new narrative of politics of identity transcends the phallocentric spiritualist, subjective idealism, and then, installs an evolutional reality within is erected a new historical materialism:

... But then she was never sure of anything, she never took a determined position, had never fought over a question of principle or anything which required high ideals or abstract thoughts. "The tradition of my people encages me in a four-walled prison and makes me the exclusive property of a man. The same tradition, or an abstracted borrowing from similar ones, exempts me from being circumcised in the same way as the African woman, whether she is Somali or Kenyan or Togolese " (Farah, 1982, p. 136).

In effect, this feminine intellection scheme in Farah's Sardines grows into a means that bed in uncertainties the particularistic and phenomenal insight, strengthening the patriarchal stasis and acquiescent conception of civilization. From this stand, the psychological and structural state of the specific exigencies of this feminine discursive method, emphasis on the creation of a system within the feminine being is bestowed a real actuality, and regarded at the same time as a thinking body inside a normative value system. Thus, throughout the moral and logic normative object of this narrative the re-appropriation and reconceptualization of the respect of social ontology has brought the female being in Sardines to yield essence and meaning vis-àvis social sphere. And then, within the narrative of a new politics of identity, they undertake an enterprise of raising a collective identity. Thereby, the synchronic and imaginative methodic approach of this inner essence feminine descriptive style exhibits the establishment of a new intellectual and sociopolitical regime of a progressive cultural prospect. This regime constitutes the new feminine state of truth within concrete possibilities that overwhelm the phallocentric authority.

\section{The Authenticity of Performative Language}

The domain of imagination within the quantitative effect determining of a mode of representation in Sardines, introduces a practical and ordinary feminine descriptive language. The conceptual acumen and empirical intelligence of this Farah's female characters display that the traditional conceptualisation scheme and custom of representation, correspondingly, base itself on a primitive radical-socialism order. Therefore, the linguistics and anthropological analytic method within evolves the new feminine voice, imposes an evolutionary diachronic and synchronic structure, which depicts the limited perspectives of the patriarchal conservative paradigmatic axes. Definitely, the gradual transformation that frames the real and the imaginary of the female being turns itself to be a psycho-sociologic, and an evolutionary dynamism that transcends the phallus collective imaginary myth. Therein, the formative basis of the new feminine language identifies the distinctive and expressive pathological aspects inside the traditional perception of genre of categorization. Within this respect, Farah writes: 
"Because I am circumcised. Do you know what that means? Infibulated."

... "I suffer this humiliation, this inhuman subjugation of circumcision; you can never know how painful it is unless you've undergone the operation yourself. But must every woman in the world suffer this act of barbarism in order to know the suffering it entails, every woman whether she is Arab, Malay, African, American? A great majority of Africa's female population suffers complication arising from infibulation. It's not racial. Suffering is human Farah, 1982, pp. 186-187).

Thus, the ontological argumentation in the run of Sardines involves in a given way, a feminine aptitude, and aesthetic abstraction with regard to the traditional narrative and form of representation. Consequently, the scientific value and incline of this feminine performative language lies in its propensity to put into view the psycho and sociological organizing dynamism of knowledge. This realm becomes furthered when Farah writes: "She took him by the hand and led through life's unread guides. It was then that he said Medina was a grey-eyed stork, gobbling words that she believed it was books and learning that would save the world from imminent self-destruction [13]". The realism of the new discourse of women in Sardines emphasizes the forceful of deconstructing the innermost and historical epistemological conception of truth, value and representation. Obviously, the social transformation underpinning the feminine psycholinguistic system in this narrative encompasses a thorough reconfiguration regarding the domain of collective epistemology. Within this respect Asma Abbas argues that:

That is, it is on the suffering of the needful subjects of liberalism, imperialism, and colonialism that edifices of society as we know it are built-edifices that claim their vital health as they reek of dead suffering and extract the labor of our senses. And that, in then seeking to save these constructions, we commit the gravest inhumanity when we cease to have any senses left for the living suffering... The limits of the political, then, are not reliant on epistemic assessment but are experienced relationally and aesthetically as a question of the nature of our very being - the degree to which our senses contest the imposed modes of the presence and absence of suffering is the degree to which we are political (Abbas, 2010, p. 4).

Through this grasp, the new politics of identity within this performative language ensures the structuration of a feminine legalism and progressivism line, which moves away the phallocentric paradoxical perception of collective epistemology.

In this run, the dialectic materialism in the inner feminine apperception of the object of cognizance, exhibits the real requirement of a new realm of reflective intellectuality. Beyond the unconscious perception of gender categorization, the implemented feminine performative language, through its approach of social construction of active invisibility installs the paradigms of social liberalism. This theory of reference dismantles the traditional referential cognitive system, in a sense; the contemporary feminine models and communication overwhelm the androcentric conventional values. By moving away, the egocentric and nominalist patriarchal principles, and by shifting the paradigms of psychological experience in relation to symbolic order, the materialist realism of the new feminine discursive intelligence shoulders a re-articulation of politics identity and a shifting authority relation. Through this deviating aptitude the feminine performative language in Sardines substantiates and determines women's essentiality within a modeling deconditioning process of the patriarchal socio-political orthodoxy:

" 'In the pertinence of her homestead,' you used to say, 'my mother stands in the shade of her purdah peeping through holes in her heart.' You used to add that I' am one of the excluded and you were of the included."

"Yes?"

"You are a prisoner of your principles and your secret dream, Medina; I am a prisoner of a tradition, that I won't deny. One is always a prisoner of one thing or another: a prisoner of acquired habits or a prisoner of the hope which chains one " (Farah, 1982, p. 144).

Therein, it appears that the feminine descriptive and political discourse follows a structural and formalized language, which inserts itself in a pure logic of deconstructing the phallocentric gender binary subdivision and the fixative conception of identity. Through the traditional division of history, it becomes clear that Farah's female characters move according to the effect of distance, annihilating the phallus collection of rules. This fact correspondingly, shows the feminine embryonic image, involved in an analytical method ingrains a state of rebuttal, which observes identity categorization as the midpoint of the patriarchal conjectural structures of ostracism inside gender difference construction. In this perspective, the underlying feminine language in this narrative of identity becomes a new construction of practice, an interpretative mechanism that observes the pattern of unconventionality and tolerance of belief as the new means of identity construction and self-realization. It is in this realm we observe relevant Agnes Ngoma Leslie argumentation when she develops that:

The first is that formal democracy may not encourage drastic change, because when it is not fully institutionalized, any call for radical change poses a threat to the system. In Botswana the "radical" change 
would not necessarily be seen as a hurried changing of the laws, but the acceptance of "disruptive ways" of seeking change, as exhibited by the women's movement. The second is that the disjuncture between state and society, identified above as a main feature of African politics exists also in Botswana, although that country is usually not considered a "typical" case. Thus whether in democratic or undemocratic environments, women seeking change have had to resort to culturally novel kinds of tactics in order to make an impact (Leslie, 2006, p. 8).

Subsequently, this transgressive method becomes a central organism within which the patriarchal systematic and normative attitude and its ethical principles concerning gender dichotomy construction undergo a series of depreciation that leads to a socio-political devaluation. The feminine analytico-deductive approach in the course of Sardines implements a structured methodic and intellectual construction of the sphere of active invisibility and the basis of politics of identity. As a result, the feminine imaginary liberalism constitutes a scientific and genetic epistemology that voluntarily emphasizes psycho-sociological understandings to install new paradigms of socio-political and relational components.

\section{5- Conclusion}

Through his writing policies, Nuruddin Farah develops a new disposition and inward realism of African women, particularly Muslim women. The realm of Sardines demystifies the Muslim phallocentric social construction by implanting a feminine narrative, which evolves from the conception of a new politics of identity. In this respect, the emerging feminine imagination progressiveness moves away from the patriarchal conservative symbolism, religious, legal, and linguistic ethnology to insert its socio-political state within the sphere of political liberty and conscious liberality. The discursive method that underlines this empirical process displays the feminine imagination liberality goes beyond the respect of constructing a system of negotiation.

The intimate structuring of imagination, and the truth of history becomes an essential scale within the feminine being unveils, a progressive intellectual form that detaches itself from the patriarchal theoretical and practical contradicted sphere of influence. Through a new psycholinguistic arrangement, the feminine being in Sardines explicitly, designates the patriarchal moral and normative logic to be inserted in a radical depravity, which ensures the enactment of theoretical contradictions that result in the systematization of gender difference.

In this stand, through the principles of difference and within the representation form of domineering and dominated the implied feminine voice in Sardines removes itself from the legal, traditional formalism, in the dynamic to insert the certainty of her discourse in the center of psychological structuralism form. This intellectual input adapts itself in a contemporary context within the notion of self-reappropriation and deconditioning the perception of the other, impels a structural transfiguration of the patriarchal symbolic order, and installs a purpose of cultural revisionism.

\section{References}

[1] Abbas, A. (2010). Liberalism and human suffering: materialist reflections on politics, ethics, and aesthetics. Springer.

[2] An-Naim, A., \& Hammond, J. (1989). Cultural Transformation and Human Rights in African Societies". In An-Naim, A. (ed.), Interpreting Women's Lives: Feminist Theory and Personal Narratives. Bloomington and Indianapolis, Indiana University Press.

[3] Barbre, Joy Webster et. al. (1989). Origins". In Personal Narratives Group, (ed.), Interpreting Women's Lives: Feminist Theory and Personal Narratives. Bloomington and Indianapolis, Indiana University Press, pp. 3-15.

[4] Farah, N. (1982). Sardines. London, Heinemann.

[5] Fellmeth, A. X. (2000). Feminism and international law: Theory, methodology, and substantive reform. Hum. Rts. Q., $22,658$.

[6] Greiff, S. (2010). No Justice in Justifications: Violence against women in the name of culture, religion, and tradition. Resource Paper, Global Campaign to Stop Killing and Stoning Women, 1-44.

[7] Johnson, P. (1990). From Virginia Woolf to The Post-Moderns: Developments in a Feminist Aesthetic. In Sean Sayers, et. all. (ed.) Socialism, Feminism and Philosophy: A Radical Philosophy Reader. London, New York, Routledge, p. 100.

[8] Kynsilehto, A. (2008). Islamic feminism: current perspectives. A. Kynsilehto, 96, 9-13.

[9] Leslie, A. (2006). Social Movement and Democracy in Africa: The Impact of Women's Struggle for Equal Rights in Botswana". In Molefi Asante (ed.) African Studies: History, Politics, Economics, and Culture. New York and Londond, Routledge.

[10] Mohanty, C. (1991). Cartographies of Politics of Struggle: Third World Women and the Politics of Feminism. In Mohanty, C. et. all. (ed.). Lourdes, Bloomington, Indiana University Press.

[11] Najmabadi, J. (2007). (ed.), The Encyclopedia of Women and Islamic Culture, vol. IV, Leiden-Boston: Brill.

[12] Paludi, M. (2010). (ed.), Feminism and Women's Right Worldwide. Vol. I. Santa Barbara, California: Praeger An Imprint of ABC-CLIO, p. XV.

[13] Polatnick, M. (1996). Diversity in Women's Liberation ideology: How a Black and White Group of the 1960's Viewed Motherhood". In The University of Chicago Press, No. 3. 
[14] Abib, S. È. N. E. (2020). A Gender-Sex System that afrocentralizes the Issue of a Traditional Female identity. The Case in Nawal El Saadawi's Woman at Point Zero and Nuruddin Farah's From a Crooked Rib. International Journal of Linguistics, Literature and Translation, 3(5), 78-86. DOI: 10.32996/ijllt.2020.3.5.9

[15] Wadud, A. (2006). Inside The Gender Jihad: Women's Reform in Islam". In Safi, Omid (ed.), Islam in the Twenty First Century. United States of America, One World Oxford. 